\title{
Numerical Study of the Circumferential Fuses Used in Steel Repairable Buildings with Seesaw Motion
}

\author{
Hossein Kazemifarda (iD \\ Mahmood Hosseini ${ }^{\text {b* }}$ \\ Masoud Nekooei ${ }^{a}$ \\ Behrokh Hosseini Hashemi $^{\text {b }}$ \\ a Department of Civil Engineering, Science and Research Branch, Islamic Azad University, Tehran, Iran. E-mail: h_kazemifard@yahoo.com, \\ msnekooei@gmail.com \\ ${ }^{b}$ Structural Engineering Research Center, International Institute of Earthquake Engineering and Seismology (IIEES), Tehran, Iran. \\ E-mail: hosseini@iiees.ac.ir, behrokh@iiees.ac.ir \\ ${ }^{*}$ Corresponding author
}

http://dx.doi.org/10.1590/1679-78255391

\begin{abstract}
Structural fuses and rocking system are used in order to reduce the building response to earthquakes and damage guidance. In the proposed seesaw motion system, which is similar to the rocking system, the building columns, in top of the foundation, have been removed and a central support and structural fuses are used around the building instead of them. The main purpose of creating this system is that the structural components remain elastic during the earthquake and nonlinear deformations occur in circumferential structural fuses it means that, it is possible to replace damaged fuses after the earthquake and exploit the building in a short time and at a lower cost than the construction cost of the whole building. In this research, the specification of a kind of structural fuse have been investigated and its application in the building with a seesaw system is studied under the influence of the near-field earthquake. After reviewing the fuses, it was observed that, the maximum absolute acceleration of roof and the base shear are significantly reduced in this system; however, the relative drift of floors in some buildings has increased but is lower than the permitted limit.
\end{abstract}

\section{Keywords}

Seesaw motion, Structural fuse, Nonlinear time history analysis, Seismic vulnerability, Repairable building

\section{Introduction}

The purpose of the current seismic design codes in designing and performing buildings against ground motions in earthquakes is to dissipate the seismic energy through their non-elastic behavior. Design and implementation of structures based on design codes will increase the energy absorbability and structural ductility. Therefore, according to this design philosophy in buildings, during strong earthquakes, buildings drop out of the range of elastic behavior and high displacements occur to dissipate seismic energy.

In severe earthquakes, structures which do not observe seismic design codes suffer general damage. However, in buildings where the regulations of design and implementation have been observed, due to the non-elastic behavior of the structure, plastic hinges are locally formed at the points where they causes non-elastic displacements while the expansion of these plastic hinges causes the damage in the structure. Therefore, the following problems occur in these buildings after the severe earthquakes: 
1. Due to the creation of large permanent displacements in the structure, and also the local failure of some members, the building cannot be useful anymore.

2. There is no possibility of repair in buildings and there is no other way than destruction and renovation.

3. Excessive costs should be spent for destruction, dismantling, and transfer of waste to the appropriate location as well as heavy financial resources must be considered for constructing new buildings.

4. Due to the destruction of buildings, a large number of people are displaced for temporary accommodation, and the health, medical, economic, security and psychological problems are some of the adverse consequences of design and implementation in the event of major earthquakes.

Of course, all of these items are mentioned for buildings which have observed seismic regulations otherwise many casualties are expected in other buildings. Therefore, the purpose of this study does not include all buildings with any level of seismic risk rather, only more important buildings located in areas with high seismic risk levels.

The damage can be reduced by using different methods, such as the use of seismic isolator or active or passive control systems in the structure. But so far, they have been used in very few of the world's existing buildings due to their high cost. Therefore, the other method is to guide the damage and the use of energy absorption systems in certain elements which have already been specified by the designer, concerning the damage is concentrated in moderate or heavy earthquakes applied to the structure and it prevents its expansion in the entire structure.

Designing and constructing buildings to be reconstructed easily and quickly after an earthquake with a reasonable cost is considered as an alternative way for keeping the seismic performance of buildings at IO level or achieving earthquake resilient buildings. In this regard, 'Deliberate Directing of Damage' (Hosseini and Alyasin 1996) or its updated version 'Directed-Damage Design' (DDD) (Hosseini and Ebrahimi 2015) is considered as an appropriate way for creating the desired repairable buildings and DDD method are used in this research. Based on this approach, a condition should be created to direct and guide the damage to some pre-decided and specific parts (structural fuses) related to the building structure to keep its main members such as columns, beams, and bracing elements intact. In this way, a quick and easy repair of the building structure with little cost is possible even after a major earthquake.

Goodfellow et al. (1970) worked on the applications of fuse inserts in seismic design of reinforced concrete structures. The use of structural fuses (SFs) was further developed by Fintel and Ghosh (1981). During the last two decades, SFs have been widely used in various structural systems although the location considered for installing the SF has been mostly ranged between the bracing elements and beams (Vargas and Bruneau, 2004) or in bracing elements (El-Bahey and Bruneau, 2011).

Although, there are many studies on rocking motion, all of which focus on reducing the seismic response of rocking system. Clough and Huckelbridge (1977) investigated a seismic analytical and laboratory study for a three-story steel frame, which allowed the uplift of the column, and significant reduction was observed in the earthquake load compared to the fixed-end columns. Midorikawa et al. (2006) conducted a laboratory test of the shaking table on the seismic response of braced steel frames with the possibility of columns uplift, it was observed that the base shear is reduced by $52 \%$ compared to the fixed-end column case and the roof displacement remained almost constant. Tremblay et al. (2008) investigated the use of a viscous damper under braced steel frame columns with rocking motion on model 1:2 and drifts remained in the range given in regulations. Midorikawa et al. (2009) examined the rocking motion by considering a type of a flexible column base plate, the reduction of the base shear in this system and the equivalent of the drift of the frame relative to that of the rigid column base plate was observed.

Hosseini and Farsangi (2012) examined the telescopic columns in buildings with seesaw behavior where, response of buildings to the extent in buildings using seismic isolator was decreased. Hosseini and Bozorgzadeh (2013) investigated a kind of energy dissipator, called DADAS, at the base of the columns used in buildings with rocking motion and they were successful in decreasing the seismic response of the structure. The plates are used in double form in this dampener. Hosseini and Kherad (2013) examined the behavior of the fuse installed in the center of the buildings with rocking motion.

Eatherton et al. (2014) designed a self-centering control system in braced steel frames with rocking behavior where the bracing frame system remained in the elastic state due to the earthquake, and earthquake energy is dissipated by the inter changeable fuses used in the structure. Hosseini et al. (2016) investigated the 3 types of 7, 10, and 14-story buildings with the seesaw motion system, where a central support was used in the middle of the building and fuses were used under all columns and, decreased acceleration and relative displacement of the floor and plastic joints compared to the conventional building was observed in the analysis. 
Recently Akbari et al. (2018) propose a new beam to column connection which has slit dampers to increase ductility and moment capacity of structures. Ductility of connections causes to dissipate more energy before failure of connections.

In this research, the characteristics of the SFs and the seismic performance of 3, 5, 7-story steel buildings are investigated regarding of seesaw motion.

\section{The proposed Structural Fuse}

In this research, nonlinear fuses are used to absorb earthquake energy around the building and under the columns, Hosseini and Alavi (2014). In Figure 1, structural fuse components have been shown which include the following components:

1. External shell is fixed to the foundation.

2. The central core is connected to the columns of the building and is movable.

3. The triangular plate is between the external shell and the central core, and its plastic deformation causes energy dissipation.

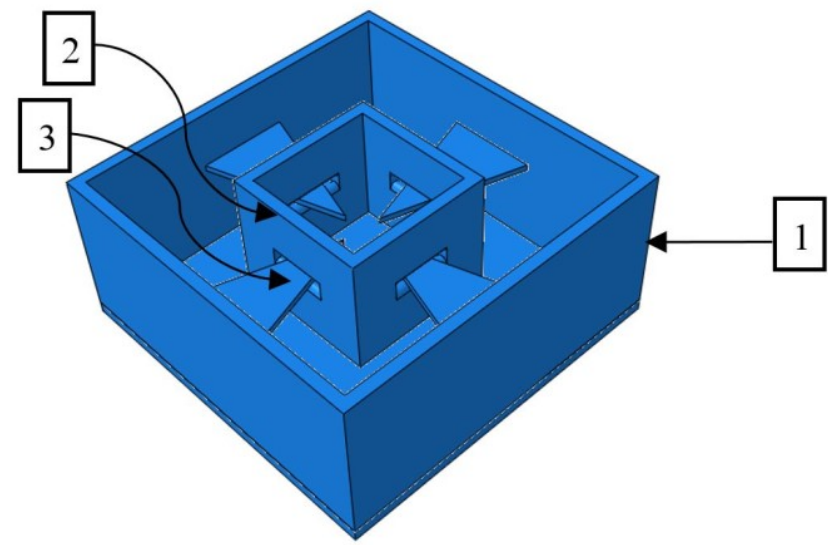

Figure 1: Fuse components, 1 - external shell, 2 - central core, 3 - triangular plate

The triangular plate is completely connected to the external shell, but has not connection with the central core, and the central core is relying on the triangular plate and is simply in contact with them. The number of triangular plates in each level is 4 , if necessary, the plates can be used in several rows to increase the fuse capacity and stiffness. It is embedded in the central core of the gap, whose height is higher than the thickness of the triangular plate and the triangular plate places inside the opening.

The parameters affecting the fuse behavior and the values which are considered in this study are:

1. Specifications of the steel of fuse components: The type of steel has effect on the stiffness and ductility of the fuse. In this study, steel has been used with steel yield stress $\left(f_{y}=240 \mathrm{MPa}\right)$ and steel ultimate stress $\left(f_{u}=370 \mathrm{MPa}\right)$.

2. The width of the triangular plate: The width of the triangular plate directly affects the fuse stiffness. In this study the maximum width of the plate is considered to be 100 and $150 \mathrm{~mm}$.

3. Thickness of the triangular plate: The thickness of the triangular plate also affects the fuse stiffness. The plates are considered at the thicknesses of 5, 10 and $15 \mathrm{~mm}$ in this study.

4. Plate length: is determined based on the dimensions of the fuse, the distance between the external shell and the central core, as well as the length, which is appropriate for the large deformations of the plate, and the triangular plate do not get out of the opening.

5. The value of the gap between the triangular plate and the central core opening: the value directly affects the secondary stiffness of the fuse.

6. Distance between external shell and central core (the effective length of the triangular plate): As the distance increases, the fuse stiffness decreases, but the range of its deformations increases, the distance in this study was considered to be $100,125,150$ and $175 \mathrm{~mm}$. 
The triangular plate is equilateral, this shape was selected so that the plastic deformation takes place in larger areas of the plates, and does not concentrate at its fixed end. Geometric features of the plate are shown in Figure 2. The contact area of the triangular plate with the middle axis is rounded, as shown in Figure 3, to facilitate the movement of the plate in the opening while it undergoes excessive bending.

Given that fuse deformations in the nonlinear range causes the friction between the plate and the opening's lower and upper sides, and also the tapered form of the plate, using analytical formulation is very difficult, instead, finite element numerical modeling is used. In order to simplify the model, only one fourth of the fuse is considered instead of its whole body, due to the symmetry. On this basis, the force - displacement hysteretic diagrams of the fuse have been obtained and plotted.

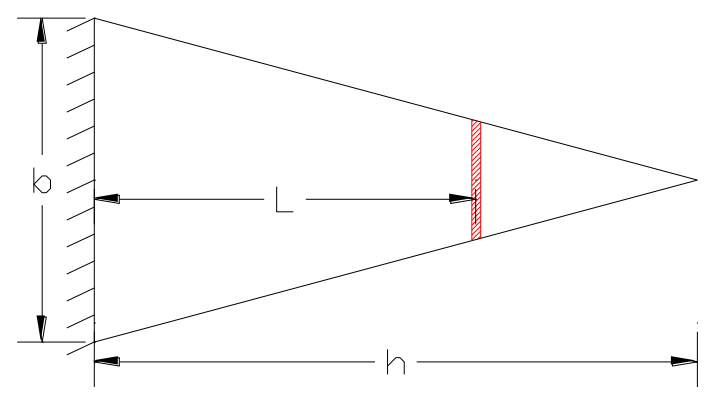

Figure 2: Specification of triangular plate

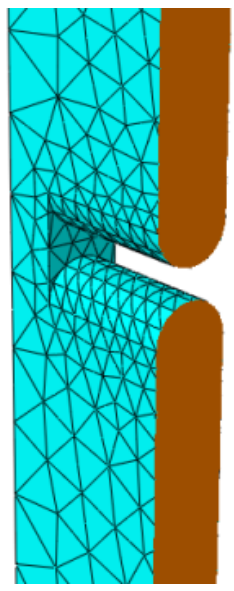

Figure 3: Section of the central core opening

\section{Fuse mechanical specifications}

\subsection{Force - displacement relationship}

The fuse performance is mainly based on plastic deformation of plates, and the friction between plates and openings' sides increases the energy dissipation. Five phases can be realized in fuse deformation:

1. From the start of displacement till the gap closure at one side, Figure 4 (a).

2. Elastic deformation of the triangular plate till the start of yielding at its fixed end, Figure 4 (b).

At the beginning of the force application, if there is some degree of gap between the triangular plate and the central core, it indicates that only one side of the plate is connected with the central core, Figure 4 (b), the behavior of the plate in this behavioral state is similar to the cantilever beam with a variable section which initially behaves linearly and as the load of the end section of the plate increases, it enters the plastic phase. According to the simplified diagram of the fuse force - displacement relationship in Figure 5, the yielding threshold value and the yielding force of the fuse are respectively represented by $\Delta y$ and $P y$. With the force $P y$ and moment $M_{P}$ of the entire section becomes plastic; it is possible to use the equation (1), (2) and (3) to obtain the amount of moment and yielding force for a beam with a rectangular and fixed section. 
$M_{P}=\frac{1}{4} b t^{2} f_{y}$

$P_{y}=\frac{M_{P}}{L}$

$P_{y}=\frac{b t^{2} f_{y}}{4 L}$

According to equation (3), the plastic force of the plate depends on the width of the plate (b), the thickness of the plate $(t)$, the yielding stress of the plate material ( $f y)$ and the distance between the outer shell and the central core (L).

3. Plastic deformation of the triangular plate till the complete closure of the gap at both sides, Figure 4 (c).

By increasing the amount of load and deformation, both edges of the triangular plate contact with the gap of the central core, Figure 4 (c), and the stiffness of the fuse has increased due to the addition of frictional force between the triangular plate and the central core, and also the resistance of the plate against bending at the gap and the tolerable force of the fuse are increased to $P$ proportionately. According to the fuse deformation diagram in Figure 5 , the values of the fusing hardening limit and the yielding force of the triangular plate are shown by $\Delta_{s}$ and $P_{s}$. The values of these parameters depend on the length of the plate and the gap between the triangular plate and the central core gap.

4. Start of friction action between the triangular plate and opening's sides, Figure 4 (d).

5. Plastic deformation of the triangular plate at opening, Figure 4 (e).

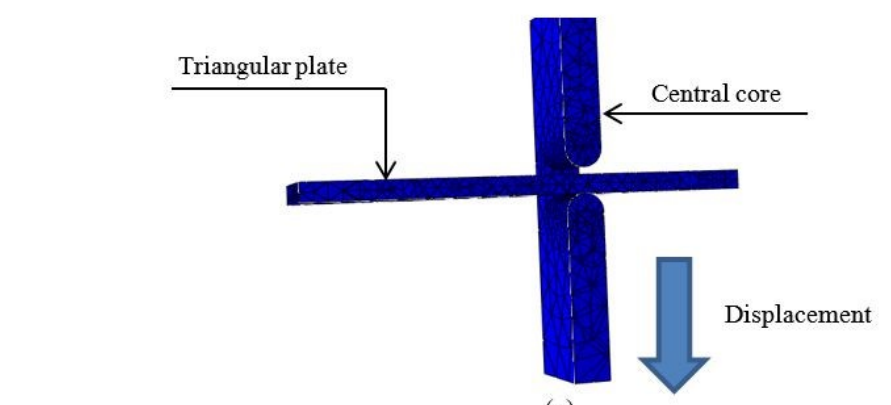

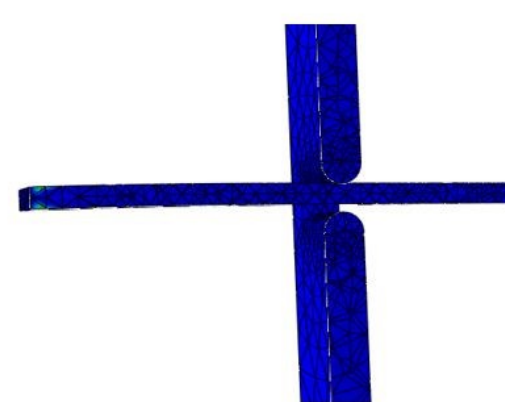

(b)

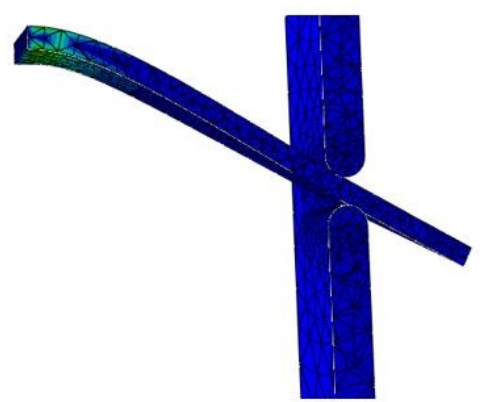

(d)

(a)

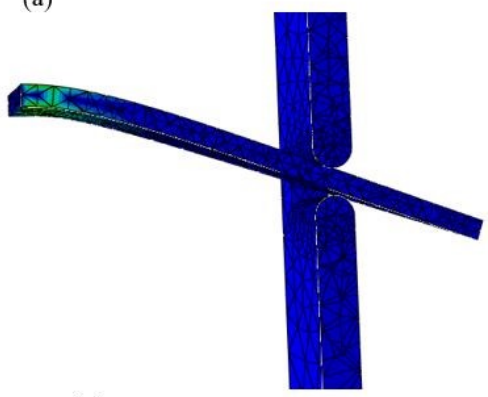

(c)

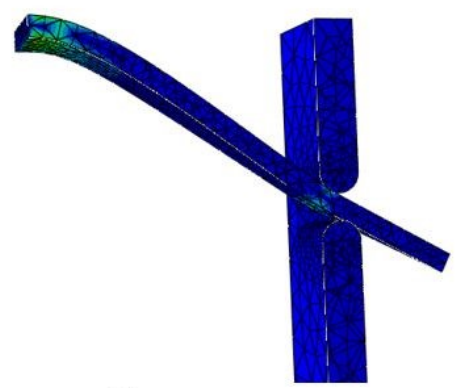

(e)

Figure 4- A section cut from deformation of a triangular plate at the beginning of the loading to end 


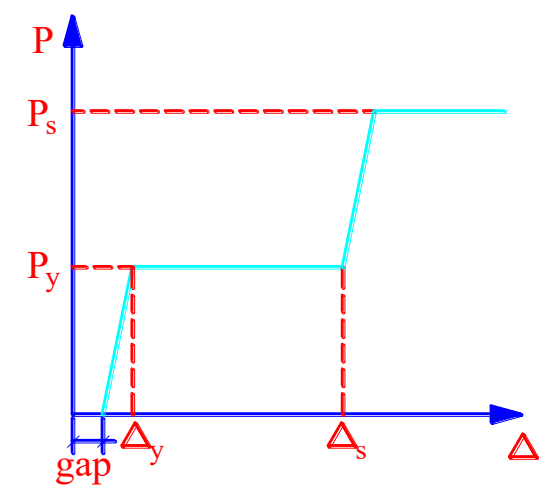

Figure 5: Simplified diagram of fuse force - displacement relationship

\subsection{Plate length $(h)$}

In Figure 2, the length of the plate is shown by $(h)$. This length is determined based on the dimensions of the fuse and the distance between the external shell and the central core, and in addition to, the length is appropriate for large deformations of the plate and the triangular plate is not removed of the central core opening, however, the length of the plate has a direct effect on the hardening region of the plate. The comparison of the effect of plate length on the force-displacement diagram of the fuse for the thickness of 5,10 and $15 \mathrm{~mm}$ has been shown in Figures 6,7 and 8 . If the value of $h$ is near $L$, there is the possibility of instability and removing the plate out of the opening practically, but as the plate length increases, the hardening force increases, too. As can be seen, the length of the plate is acceptable if the stiffness of the fuse does not decrease after the hardening region and there is constant or incremental stiffness.

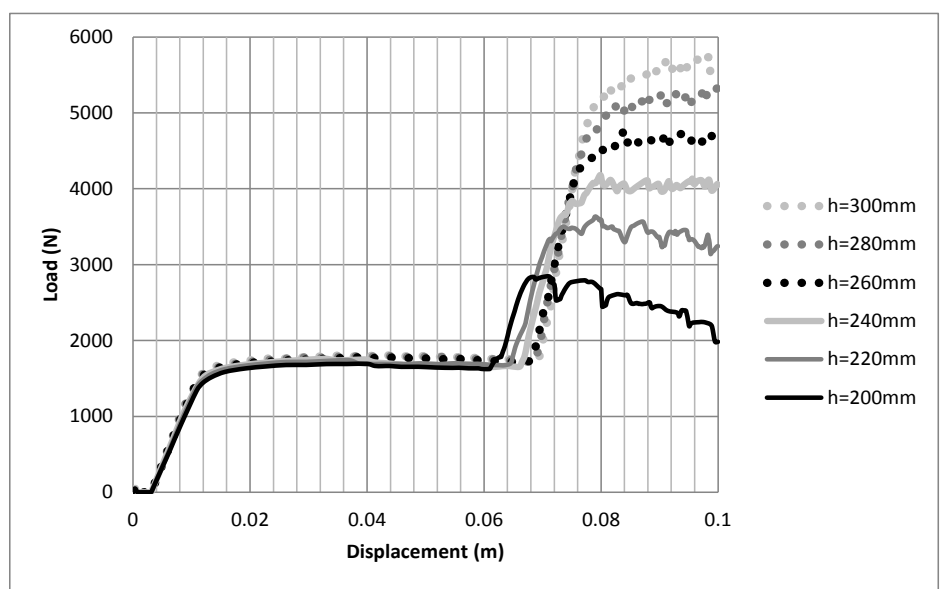

Figure 6: Comparison the effect of plate length $(h)$ on the force-displacement diagram of the fuse for a plate with thickness of $5 \mathrm{~mm}$

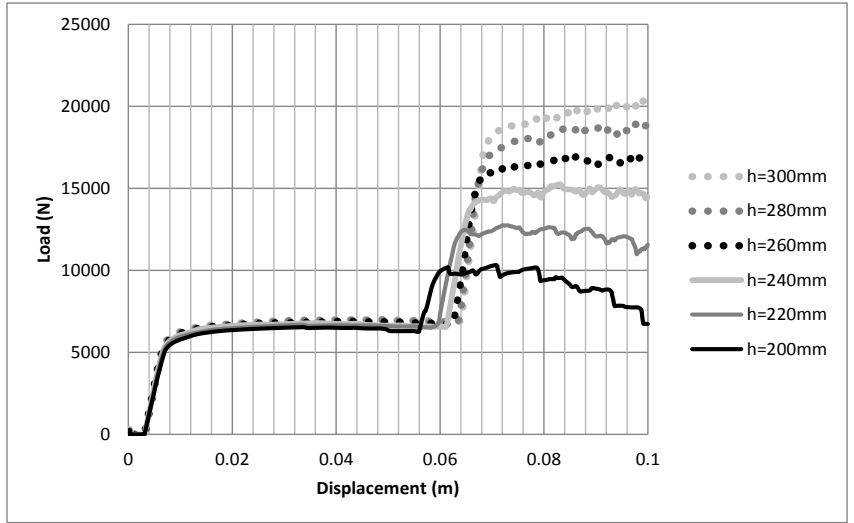

Figure 7: Comparison the effect of plate length $(h)$ on the force- displacement diagram of the fuse for a plate with thickness of $10 \mathrm{~mm}$ 


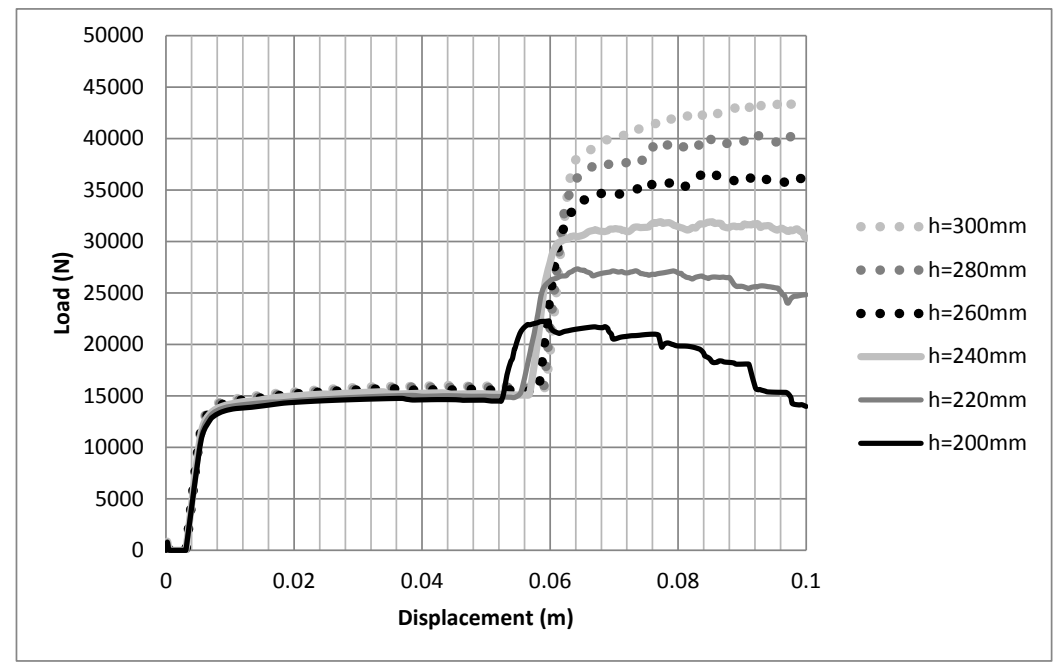

Figure 8: Comparison the effect of plate length $(h)$ on the force- displacement diagram of the fuse for a plate with thickness of 15 $\mathrm{mm}$

The force-displacement curves are converted to multi-line diagrams similar to Figure 5, so that the under curve surface is identical in both graphs. The specifications of the force-displacement diagram for different plates have been presented in Table 1. As can be seen, the values of $F_{y}$ and $\Delta_{y}$ are almost constant for each plate thickness with different lengths. Also, the minimum $h / L$ ratio for plates is 1.6 , and the slope of the graph is positive. The gap value of $3 \mathrm{~mm}$ has been considered for all models in this section. The parameters to be used are:

$P_{y}$ : Plate yielding force $(\mathrm{N})$

$P_{s}$ : Plate hardening force $(\mathrm{N})$

$K_{s}$ : The stiffness variation trend in the hardening area of the plate with positive slope of increasing stiffness and with a negative slope of decreasing stiffness

Table 1: Specifications obtained from the force-displacement diagram for different plates

\begin{tabular}{ccccccccccccc}
\hline $\begin{array}{c}\mathbf{t} \\
(\mathbf{m m})\end{array}$ & $\begin{array}{c}\mathbf{b} \\
(\mathbf{m m})\end{array}$ & $\begin{array}{c}\mathbf{L} \\
(\mathbf{m m})\end{array}$ & $\begin{array}{c}\mathbf{h} \\
(\mathbf{m m})\end{array}$ & $\mathbf{h} / \mathbf{L}$ & $\begin{array}{c}\mathbf{P}_{\mathbf{y}} \\
\mathbf{( N )}\end{array}$ & $\begin{array}{c}\boldsymbol{\Delta}_{\mathbf{y}} \\
(\mathbf{m m})\end{array}$ & $\begin{array}{c}\mathbf{P}_{\mathbf{s}} \\
\mathbf{( N )}\end{array}$ & $\begin{array}{c}\boldsymbol{\Delta}_{\mathbf{s}} \\
(\mathbf{m m})\end{array}$ & $\mathbf{P}_{\mathbf{s}} / \mathbf{P}_{\mathbf{y}}$ & $\mathbf{\Delta}_{\mathbf{s}} / \mathbf{\Delta}_{\mathbf{y}}$ & $\begin{array}{c}\mathbf{K}_{\mathbf{s}} \\
\text { slope }\end{array}$ \\
\hline 5 & 150 & 160 & 200 & 1.25 & 1670 & 11 & 2800 & 67 & 1.7 & 6.1 & Negative \\
5 & 150 & 160 & 220 & 1.38 & 1717 & 11 & 3500 & 74 & 2.0 & 6.7 & Negative \\
5 & 150 & 160 & 240 & 1.50 & 1746 & 11 & 4075 & 78 & 2.3 & 7.1 & Positive \\
5 & 150 & 160 & 260 & 1.63 & 1758 & 11 & 4450 & 78 & 2.5 & 7.1 & Positive \\
5 & 150 & 160 & 280 & 1.75 & 1776 & 11 & 5000 & 81 & 2.8 & 7.4 & Positive \\
5 & 150 & 160 & 300 & 1.88 & 1800 & 11 & 5400 & 83 & 3.0 & 7.5 & Positive \\
10 & 150 & 160 & 200 & 1.25 & 6400 & 7 & 10100 & 60 & 1.6 & 8.6 & Negative \\
10 & 150 & 160 & 220 & 1.38 & 6520 & 7 & 12400 & 64 & 1.9 & 9.1 & Negative \\
10 & 150 & 160 & 240 & 1.50 & 6700 & 7 & 14300 & 67 & 2.1 & 9.6 & Positive \\
10 & 150 & 160 & 260 & 1.63 & 6800 & 7 & 16000 & 69 & 2.4 & 9.9 & Positive \\
10 & 150 & 160 & 280 & 1.75 & 6880 & 7 & 17700 & 72 & 2.6 & 10.3 & Positive \\
10 & 150 & 160 & 300 & 1.88 & 6950 & 7 & 19000 & 73 & 2.7 & 10.4 & Positive \\
15 & 150 & 160 & 200 & 1.25 & 14500 & 5 & 21900 & 56 & 1.5 & 11.2 & Negative \\
15 & 150 & 160 & 220 & 1.38 & 14800 & 5 & 26500 & 61 & 1.8 & 12.2 & Negative \\
15 & 150 & 160 & 240 & 1.50 & 15200 & 5 & 30400 & 63 & 2.0 & 12.6 & Positive \\
15 & 150 & 160 & 260 & 1.63 & 15500 & 5 & 34000 & 65 & 2.2 & 13.0 & Positive \\
15 & 150 & 160 & 280 & 1.75 & 15700 & 5 & 37000 & 66 & 2.4 & 13.2 & Positive \\
15 & 150 & 160 & 300 & 1.88 & 15900 & 5 & 40000 & 70 & 2.5 & 14.0 & Positive \\
\hline
\end{tabular}

\subsection{The gap between the triangular plate and the central core opening}

It should be noted that, the value of the gap of the central core must be higher than the thickness of the plate for making the fuse. But the free distance has a direct effect on the stiffness and the nonlinear behavior of the fuse. Figures 9, 10 and 11 have presented force-displacement graphs of the fuse for plates with thicknesses of 5, 10 and $15 \mathrm{~mm}$ and different gap values. As seen in the Figure, The values of $\mathrm{b}=100 \mathrm{~mm}, L=150 \mathrm{~mm}$ and $h=240 \mathrm{~mm}$ have been 
considered in these diagrams, as the gap value increases, the stiffness of the fuse in the hardening region reduces and plastic deformations of the fuse increases. According to the diagrams, the gap value of 2 to $3 \mathrm{~mm}$ is appropriate for all plate thicknesses.

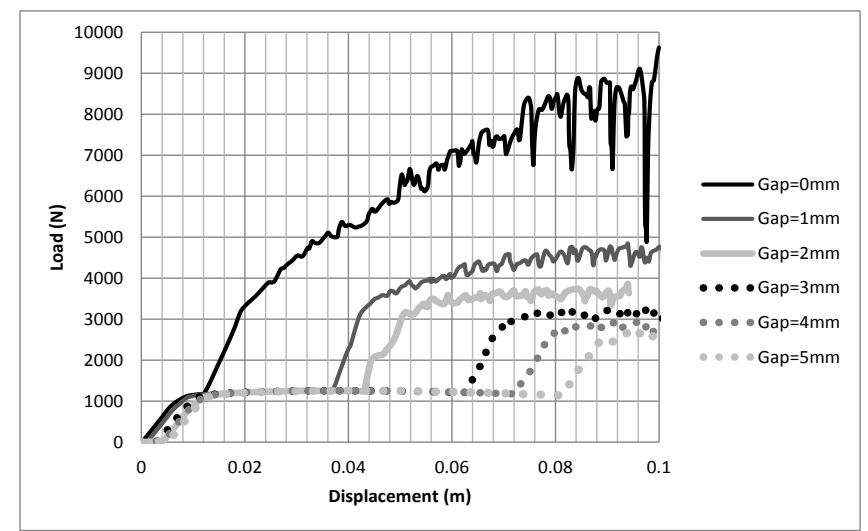

Figure 9: Comparison the effect of the gap on the fuse force-displacement diagram for a plate with thickness of $5 \mathrm{~mm}$

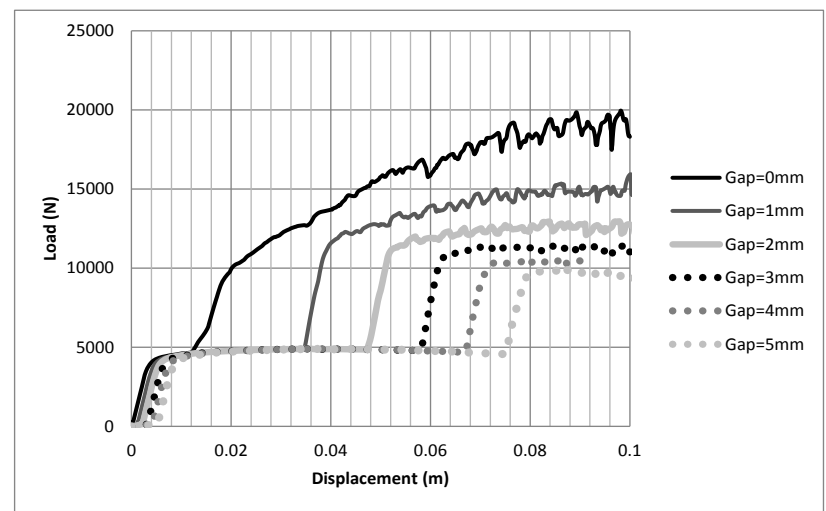

Figure 10: Comparison the effect of the gap on the fuse force-displacement diagram for a plate with thickness of $10 \mathrm{~mm}$

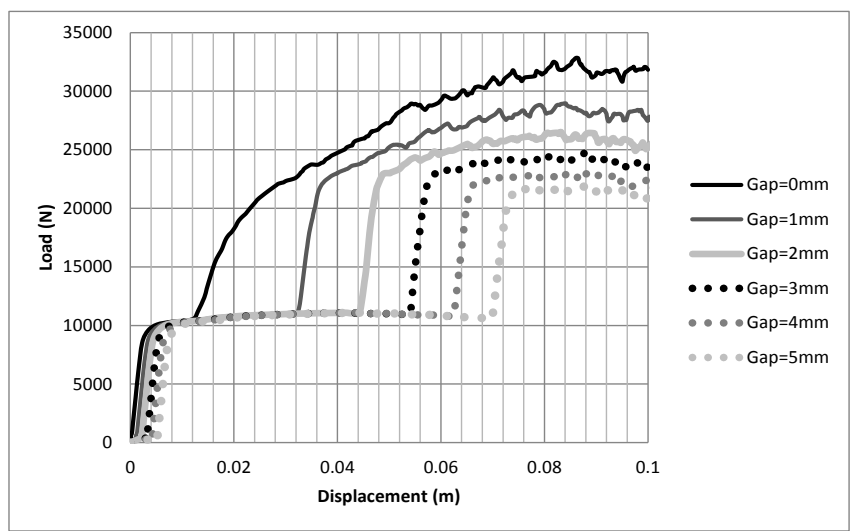

Figure 11: Comparison the effect of the gap on the fuse force-displacement diagram for a plate with thickness of $15 \mathrm{~mm}$

\subsection{Distance between external shell and central core $(L)$}

The distance between the external shell and the central core is also an important parameter in the fuse stiffness, as the distance increases, the fuse stiffness has decreased, but the extent of its deformation increases. Figures 12,13 and 14 have shown the force-displacement diagram of the fuse for plate at the thicknesses of 5, 10 and $15 \mathrm{~mm}$, and the distance between 100, 120, 140 and $160 \mathrm{~mm}$ and a gap of $3 \mathrm{~mm}$ and b=150 mm. Comparison of the figures indicates that the deformations are low at $L=100,120 \mathrm{~mm}$ and the force and displacement diagram in the hardening region shows decreased stiffness, but the rest of the distances are appropriate. 


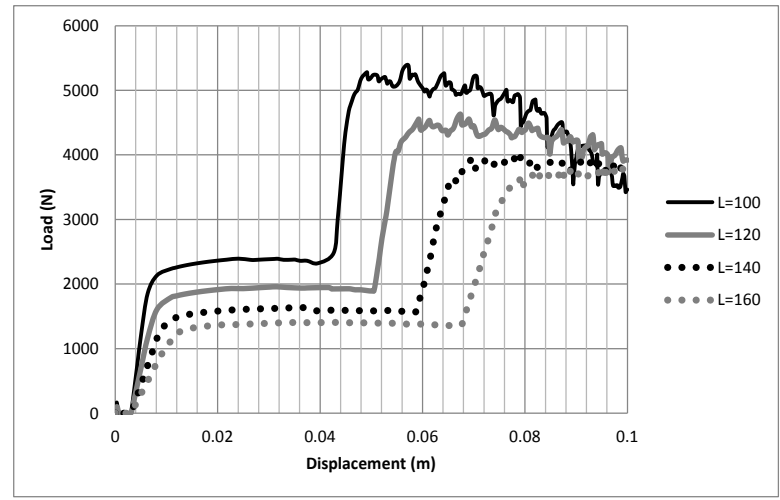

Figure 12: Comparison the effect of the distance between the external shell and the central core on the force-displacement diagram of the fuse at the thickness of $5 \mathrm{~mm}$

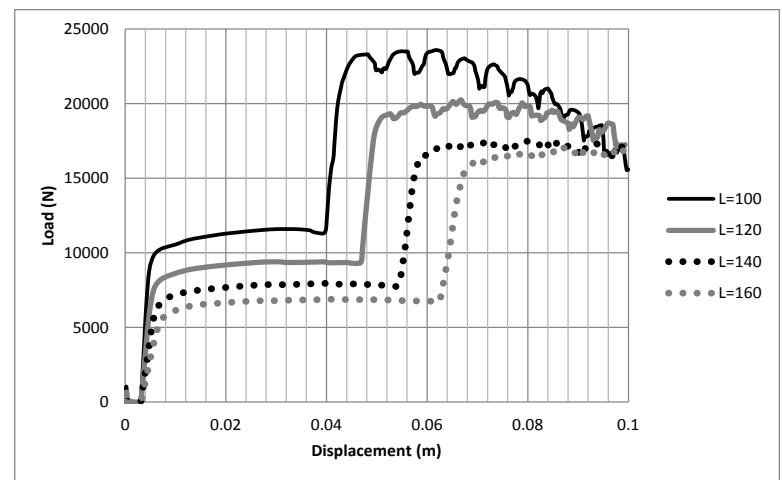

Figure 13: Comparison the effect of the distance between the external shell and the central core on the force-displacement diagram of the fuse at the thickness of $10 \mathrm{~mm}$

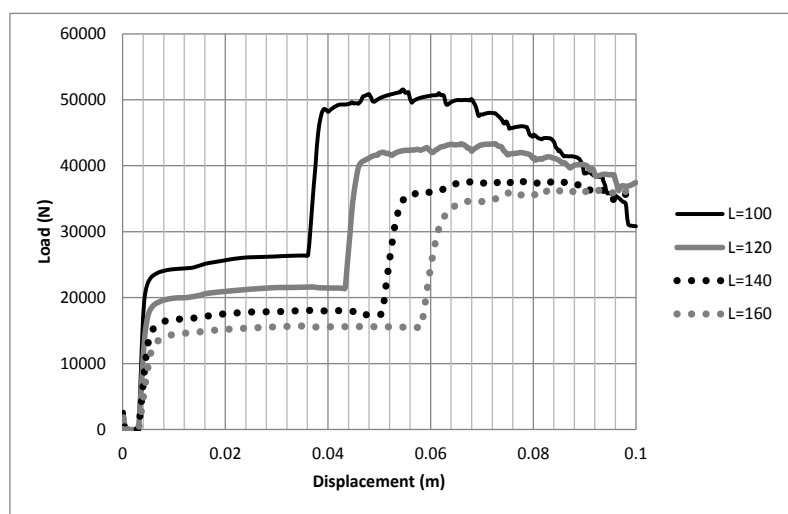

Figure 14: Comparison the effect of the distance between the external shell and the central core on the force-displacement diagram of the fuse at the thickness of $15 \mathrm{~mm}$

\section{Effect of Fuses on the Seismic Behavior of the Building with Seesaw Motion}

\subsection{Building specifications}

In order to enter the fluctuation of the building in the earthquake to the seesaw phase, fuses are installed on the column base and the middle columns, except that the central columns, are removed. The grid system of deep beams is also used to transfer the load of columns which were removed to the central support. In this research, the proposed system for regular steel buildings is dual lateral force resisting system with concentric braced frame and moment resisting frame in the plan. Figure 15 shows the three-dimensional view and Figure 16 indicates the building plan. This system has 4 main parts:

1. Central support: The central support is of great importance with regard to the removal of middle columns and the use of structural fuses on the circumferential column bases. The central support must have the ability to tolerate 
the vertical load of the building therefore, the design of the foundation and also the structural support of the central support is important.

2. Circumferential structural fuses: Structural fuses are used on the periphery column bases, whose specifications are determined according to the number of floors and dimensions of the structure.

3. the grid of orthogonal strong girders (GOSG): Due to the fact that the middle columns of the first floor are removed in order to transfer the load of the columns of the upper floors to the central support and, the circumferential columns are replaced with structural fuses, the major part of the load of these columns should be transferred to the central core, therefore, it requires a relatively rigid support for the columns that, GOSG can be consisted of strong beams or trusses.

4. Conventional structure of upper floors: This part is the same as the usual building

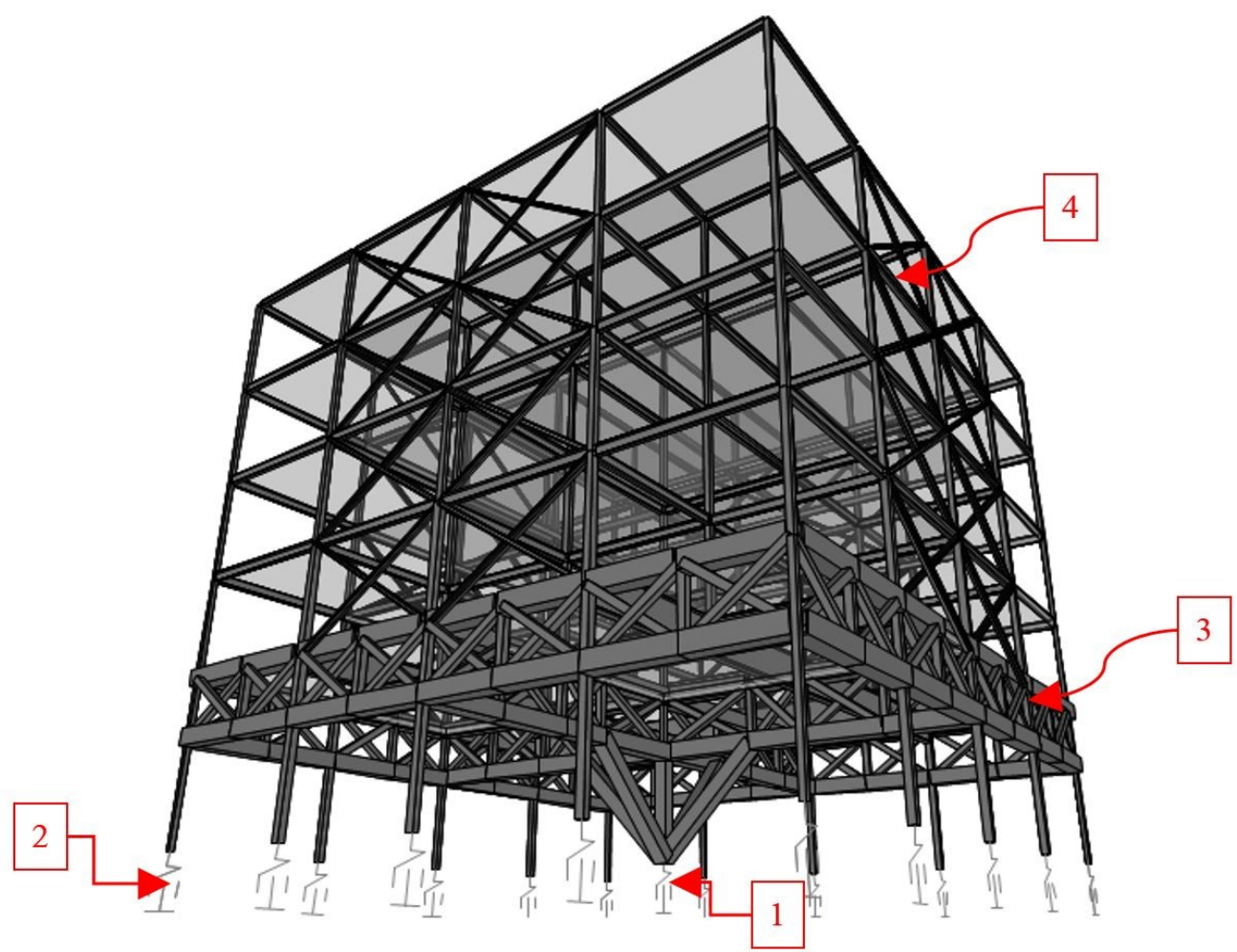

Figure 15: 3-dimensional view and components of the building with seesaw motion, 1- Central support, 2- Circumferential structural fuses, 3- grid of orthogonal strong girders, and 4- Conventional structure of upper floors

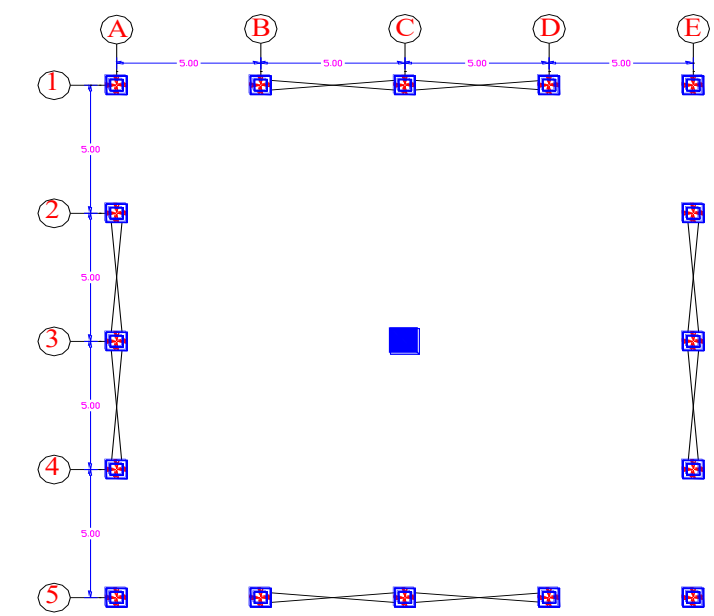

Figure 16: Building plan in base level with seesaw motion

Also the characteristics of the studied buildings have been listed in Table 2 . 
Table 2: Specifications of the studied buildings

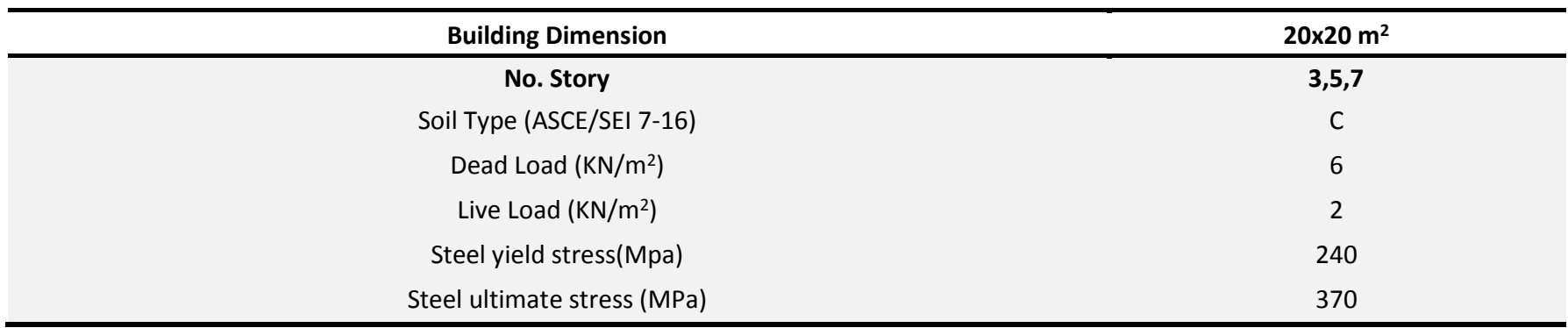

\subsection{Nonlinear Dynamic Modeling and Analysis}

In order to estimate the performance of fuses in buildings, nonlinear time history dynamic analysis under the influence of three components of accelerogram related to 7 near-field earthquakes recorded on soil type C (ASCE7-10, 2010) has been used. Specifications of the selected accelerogram are available in Table 3.

Table 3: Specifications of the selected near-field earthquakes

\begin{tabular}{|c|c|c|c|c|c|c|c|}
\hline \multirow{2}{*}{$\begin{array}{l}\text { ID } \\
\text { No. }\end{array}$} & \multicolumn{3}{|c|}{ Earthquake } & \multirow{2}{*}{$\begin{array}{l}\text { Recording } \\
\text { Station }\end{array}$} & \multirow{2}{*}{$\begin{array}{c}\text { Source } \\
\text { (Fault Type) }\end{array}$} & \multirow{2}{*}{$\begin{array}{l}P^{P G A_{\max }} \\
\text { (g) }\end{array}$} & \multirow{2}{*}{$\begin{array}{c}\text { Effective } \\
\text { Duration (sec) }\end{array}$} \\
\hline & M & Year & Name & & & & \\
\hline 1 & 6.8 & 1976 & Gazli,USSR & Karakyr & Thrust & 0.71 & 8 \\
\hline 2 & 7.6 & 1999 & Chi-Chi,Taiwan & TCU067 & Thrust & 0.56 & 23 \\
\hline 3 & 7.0 & 1992 & Cape Mendocino & Cape Mendocino & Thrust & 1.43 & 10 \\
\hline 4 & 6.9 & 1989 & Loma Prieta & BRAN & Strike-slip & 0.52 & 10 \\
\hline 5 & 6.9 & 1989 & Loma Prieta & Corralitos & Strike-slip & 0.64 & 8 \\
\hline 6 & 6.8 & 1985 & Nahanni Canada & Site 1 & Thrust & 1.18 & 8 \\
\hline 7 & 6.7 & 1994 & Northridge-01 & VA & Thrust & 0.73 & 9 \\
\hline
\end{tabular}

According to the results of the modeling, $5 \mathrm{~mm}$ plate fuse cannot be used in buildings due to their low stiffness. Therefore, fuses with plates at thicknesses of 10 and $15 \mathrm{~mm}$ are used in accordance with the specifications of Table 4 in nonlinear time history analysis.

Table 4: Specifications of the fuses used in the studied buildings

\begin{tabular}{cccccccccccc}
\hline Name & NO. rows & $\mathbf{b}$ & $\mathbf{h}$ & $\mathbf{t}$ & $\mathbf{L}$ & gap & Py & $\Delta \mathbf{y}$ & Ps & $\Delta \mathbf{s}$ \\
\cline { 3 - 9 } & & $(\mathbf{m m})$ & $(\mathbf{m m})$ & $(\mathbf{m m})$ & $(\mathbf{m m})$ & $(\mathbf{m m})$ & $(\mathbf{N})$ & $(\mathbf{m m})$ & $(\mathbf{N})$ & $(\mathbf{m m})$ \\
F1 & 1 & 150 & 260 & 10 & 160 & 3 & 27200 & 7 & 64000 & 69 \\
F2 & 1 & 150 & 260 & 10 & 160 & 3 & 62000 & 5 & 136000 & 65 \\
F3 & 2 & 150 & 260 & 10 & 160 & 3 & 54400 & 7 & 128000 & 69 \\
F4 & 2 & 150 & 260 & 10 & 160 & 3 & 124000 & 5 & 272000 & 65 \\
\hline
\end{tabular}

One of the failure criteria for buildings in nonlinear methods is the formation of plastic hinges. The rotation of the joints at the various performance levels has certain values according to the available codes and, it should be noted that the plastic rotation is the most important factor in making permanent displacements in the member. In some engineering software, the nonlinear response of the structure has been defined by the definition of plastic hinges at specific points and is applied on the structure response and non-linear behavior. In addition to applying work approximations, this simplifies the process of nonlinear analysis. According to FEMA-356 (2000), certain values have been given for nonlinear analysis methods, the modeling parameters and the quantitative acceptance criteria for each member of the structure. Considering the type of member and the performance level, the proportionality for the displacement and rotation of hinges has been determined.

First, the considered buildings were designed in the fixed-based state by the conventional method according to AISC 360-10 (AISC, 2010) provisions. Then, the proposed system is analyzed with assumption of the circumferential structural fuses of Table 4, in order to determine the minimum seismic response. There are always two limitations in design with the proposed system: 
1. The purpose of this system is to maintain the building at the performance level of Immediate Occupancy (IO). Therefore, the maximum inter-story drift is limited to $0.5 \%$ of the story height (the performance level of immediate occupancy). Of course, the drift due to the rotation around the central support is deducted from the drift. By decreasing the circumferential stiffness, drift increases that, this makes it possible to control the minimum stiffness of the circumferential fuses.

2. By increasing stiffness of circumferential fuses, topical plastic hinges may be formed in the structure and, given the fact that the purpose of designing this system is to reduce the seismic response and lack of formation of plastic joints $L S$ and $C P$, the maximum performance level of joint which was formed in the structure is limited to IO. By controlling this issue, the upper limit of the circumferential fuses is controlled.

After structural analysis of the acceleration and displacement values in the roof, the base shear, inter-story drift is extracted to compare the proposed system with the conventional building.

\subsection{Results of using frictional fuses on the behavior of buildings}

\subsubsection{Roof acceleration}

Absolute acceleration in the roof has been measured for the conventional building and the building with seesaw motion for all earthquakes and the number of floors 3, 5 and 7 and with different structural fuses. As an example, in Figure 17, the comparison of absolute roof acceleration in the 3-story conventional and seesaw building is shown for the Loma Prieta earthquake that, the decreased roof acceleration in the proposed system is quite evident. On average about 66 percent of the acceleration in the roof in the seesaw system is reduced compared to the conventional building, in all buildings and for 7 earthquakes.

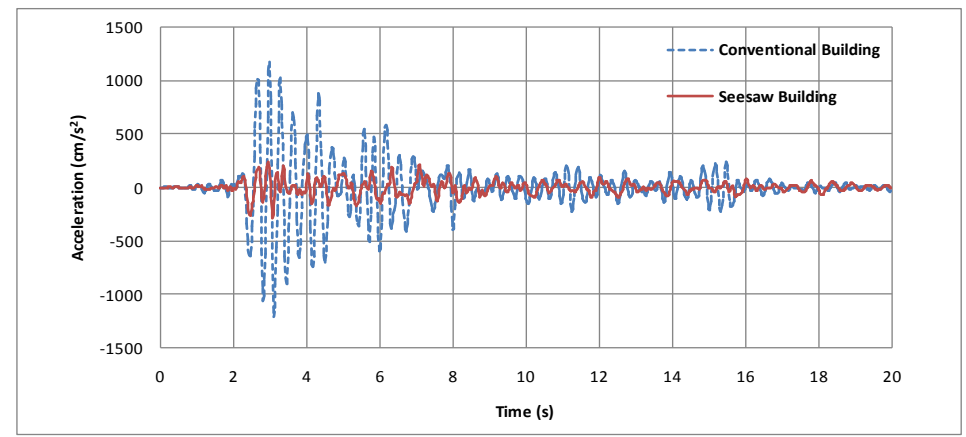

Figure 17: Comparison of absolute roof acceleration in the 3-story conventional and seesaw building for the Loma Prieta earthquake

\subsubsection{Base shear}

The base shear has been measured for the conventional building and the building with seesaw motion for all earthquakes and the number of floors of 3, 5 and 7 and with different structural fuses. As an example, in Figure 18, a comparison of the base shear is shown in the 5-story conventional and seesaw buildings for the Taiwan Chichi earthquake. On average, about $60 \%$ of the base shear in the seesaw system is reduced compared to the conventional building, in all buildings and for the 7 earthquakes.

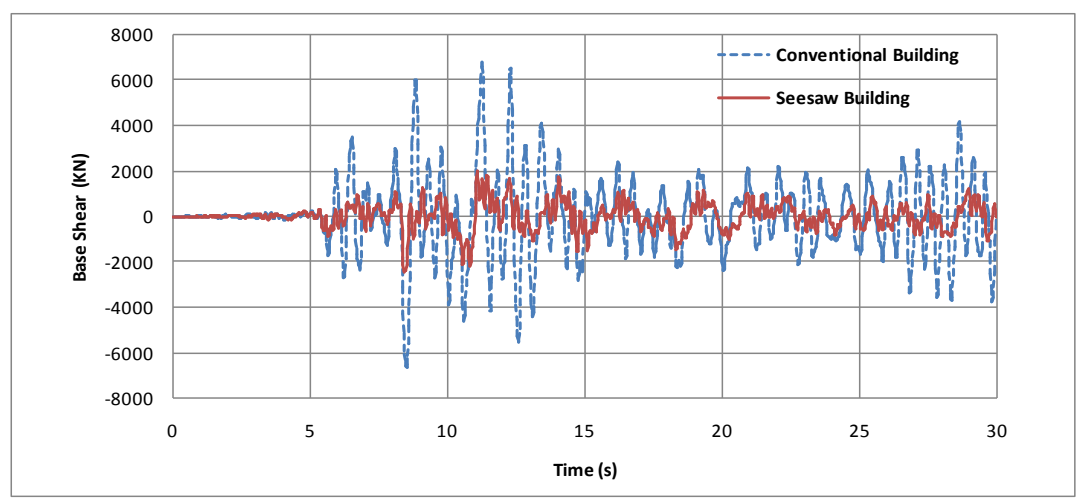

Figure 18: Comparison of the base shear in the 5-story conventional and seesaw buildings, for the Taiwan Chichi earthquake 


\subsubsection{Inter-story drift}

According to the regulations, one of the important parameters in the design of structures is the permissible Interstory drift. Comparisons of Inter-story drift in the 7-story conventional and seesaw buildings has been shown for the Northridge earthquake In Figure 19. According to this Figure, the drift of the floor has decreased by a maximum of about $45 \%$, of course, this is not the case in all buildings and in 3 and 5-story buildings, this value has increased in the seesaw building, but has not exceeded the permissible level of $0.5 \%$.

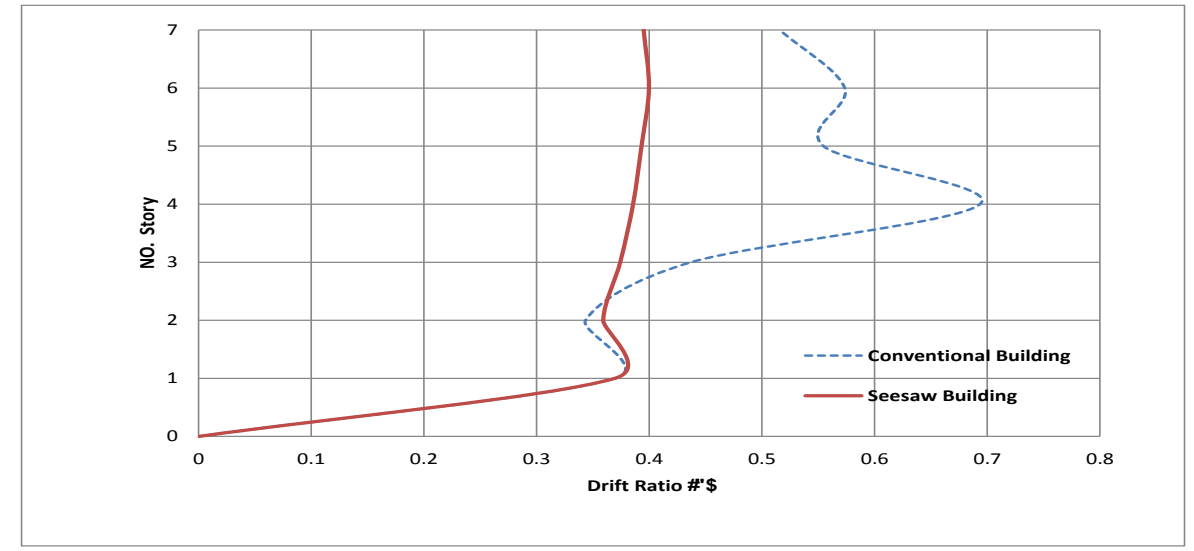

Figure 19: Comparison of relative drift in 7-story conventional and seesaw buildings for the Northridge earthquake

\section{Conclusion}

The following results were obtained by studying and modeling the finite element of the fuses and using them in seesaw buildings:

1. According to the force-displacement graph of the fuse, the hardening region of the diagram has a great effect in the prevention of the instability of the building with seesaw motion, that the tolerable force of the fuse in this region is two times more than that of the yielding limit.

2. The triangular plate of structural fuse with a thickness of 10 and $15 \mathrm{~mm}$ is well responsive in the buildings which were studied and can be used in the fuse in one or two-row form.

3. According to the results of the analysis, the minimum $h / L$ ratio for plates is 1.6 and the appropriate gap is $3 \mathrm{~mm}$.

4. On average, about $66 \%$ of the acceleration in the roof and about $60 \%$ of the base shear in the building with the seesaw system are reduced compared to the conventional building in all buildings and for the 7 near-field earthquakes.

5. The relative drift of the floor in the 7-story seesaw building is reduced compared to the conventional building. This value has increased, but does not exceed $0.5 \%$ in 3 and 5 -story buildings.

\section{References}

AISC (2010), Specification for Structural Steel Buildings, American Institute of Steel Construction; Chicago, IL.

Akbari, H., Izadinia, M., Memarzadeh, P. (2018). Experimental and numerical study of I-shape slit dampers in connections. Latin American Journal of Solids and Structures, 15(11), e131

ASCE7-10, (2010). Minimum Design Loads for Buildings and Other Structures, American Society of Civil Engineers: Reston, VA.

Clough, R.W. and A.A. Huckelbridge, (1977). Preliminary experimental study of seismic uplift of a steel frame. Earthquake Engineering Research Center, College of Engineering, University of California.

Eatherton, M.R., et al. (2014). Design concepts for controlled rocking of self-centering steel-braced frames. Journal of Structural Engineering, 140(11): p. 04014082.

El-Bahey, S. and M. Bruneau (2011). Buckling restrained braces as structural fuses for the seismic retrofit of reinforced concrete bridge bents. Engineering Structures, 33(3): p. 1052-1061. 
FEMA-356, (2000). Federal Emergency Management Agency (FEMA), Pre-standard and Commentary for the Seismic Rehabilitation of Buildings, Washington. D.C.

Fintel, M. and S. Ghosh. (1981). the structural fuse an inelastic approach to earthquake-resistant design of buildings. Civil Engineering ASCE, 51(1): p. 48-51.

Goodfellow, R., et al. (1970). Applications of fuse inserts in seismic design of reinforced concrete structures. WIT Transactions on the Built Environment, 41.

Hosseini, M. and E.N. Farsangi. (2012). Telescopic columns as a new base isolation system for vibration control of high-rise buildings. Earthquakes and Structures, 3(6): p. 853-867.

Hosseini, M. and H. Ebrahimi. (2015). Proposing a yielding-plate energy dissipating connection for circumferential columns of steel rocking buildings and investigating its proper properties by nonlinear finite element analyses. 11th International Workshop on Advanced Smart Materials and Smart Structures Technology. Illinois, USA.

Hosseini, M. and S. Alavi, (2014). A kind of repairable steel buildings for seismic regions based on buildings' rocking motion and energy dissipation at base level. International Journal of Civil and Structural Engineering- IJCSE, 1(3).

Hosseini, M. and S. Alyasin. (1996). Deliberate Directing of Damage in Lifeline Systems Subjected to Earthquakes. In Proceedings of the Hazard-96 Symposium, Toronto, Canada.

Hosseini, M. and S. Bozorgzadeh. (2013). An innovative design for repairable regular steel buildings by using a 4-cell configuration structure with some inclined columns at base level, equipped with double-ADAS devices, and security cables at corners. Proceedings of the Thirteenth East Asia-Pacific Conference on Structural Engineering and Construction (EASEC-13).

Hosseini, M. and S. Kherad. (2013). A multi-stud energy dissipating device as the central fuse to be used in short-to mid-rise regular steel buildings with rocking motion. in International Van Earthquake Symposium, Van, Turkey.

Hosseini, M., M. Fekri, and M. Yekrangnia, (2016). Seismic performance of an innovative structural system having seesaw motion and columns equipped with friction dampers at base level. The Structural Design of Tall and Special Buildings, 25(16): p. 842-865.

Midorikawa, M., et al. (2009). Three-dimensional shaking table tests on seismic response of reduced-scale steel rocking frames. Proceedings of the 3rd International Conference on Advances in Experimental Structural Engineering.

Midorikawa, M., et al., (2006). Shaking table tests on seismic response of steel braced frames with column uplift. Earthquake engineering \& structural dynamics, 35(14): p. 1767-1785.

Tremblay, R., et al. (2008). Innovative viscously damped rocking braced steel frames. Proceedings of the 14th World Conference on Earthquake Engineering, Beijing, China.

VARGAS, R. and M. BRUNEAU. (2004). Seismic response of single degree of freedom structural fuse systems. 13 th World Conference on Earthquake Engineering. Vancouver, B.C., Canada. 